\title{
1 A liquid 2,4-D pulse increased shoot and root regeneration from leaf explants of
}

2 adult Prunus rootstocks

3

4 Lidia Pascual \& Juan A. Marín*

5 Pomology, Estación Experimental de Aula Dei (CSIC), Apartado 202, 50080 Zaragoza,

6 Spain

$7 \quad$ *Author for correspondence (Tel: +34 976 716128; Fax: +34 976 716145; E-mail:

8 jmarin@eead.csic.es)

9

10 Abstract

11 Regeneration of adult plant material is one of the main limitations for successful Prunus

12 rootstock transformation. Results herein show that a liquid pulse (90 min) of 2,4-D (1.7

$13 \mu \mathrm{M}$ ), applied to leaf explants, greatly improved shoot regeneration in Marianna 2624

14 (Prunus cerasifera x munsoniana) and Myrobalan 605 AD (P. cerasifera); and induced

15 roots in Adafuel (P. x amigdalo-persica) when placed in regeneration medium. Whole

16 leaves and basal leaf explants of Marianna 2624 regenerated shoots in a higher

17 proportion of explants after the pulse (up to $58.9 \%$ in whole leaves) than medium or tip

18 leaf segments, whereas the leaf tip was the explant that showed less regeneration. In the

19 regeneration medium, in the presence of BAP, NAA was more effective than 2,4-D. The

20 application of an auxin pulse is a simple method that could enhance adult plant

21 regeneration in commercial rootstocks.

23 Key words:

24 Leaf explant type, induction treatment, genotype effect, adventitious organ

25 differentiation, auxin pulse. 
28 Regeneration of stone fruit trees is usually difficult to achieve and, while success has been obtained using juvenile tissues, few reports exist from mature plants (Scorza et al., 1995a). On the other hand, biotechnological gene transfer in fruit trees is a convenient technique, since conventional breeding methods find frequent endogenous barriers to interspecific hybridization that make difficult gene interchange between species (Perez and Moore, 1985). Thus, great effort is being made to get appropriate regeneration protocols for these plants and recent reports have been published for different Prunus species, as in almond (Ainsley et al., 2000), apricot (Perez-Tornero et al., 2000), cherry (Gutierrez-Pesce et al., 1998; Hammatt and Grant,1998; Grant and Hammat, 2000; Tang et al., 2002), and peach (Gentile et al., 2002). Some of these works, as well as other previous reports on apricot and plum (Antonelli and Druart, 1990; Escalettes and Dosba, 1993) involved multiple steps and manipulations that include transfers to different media, successive changes in environmental conditions, and preconditioning of source plant material, suggesting that organogenesis is affected by several factors, some of them not precisely defined. This fact could explain in part the difficulty to reproduce a described protocol when changes are made in any of different factors affecting the plant material and origin, or even the laboratory environment.

A simple, reproducible, and effective protocol for these woody species is needed to apply biotechnology to mature plants successfully. However, differentiation of adventitious organs in adult plant material is difficult to achieve (Rajasekaran and Mullins, 1982). Promising results have been reached by using different strategies including (1) preconditioning of plant material that precedes the regeneration treatment

50 (Sriskandarajah and Goodwin, 1998); (2) several changes in both lighting conditions

51 and hormonal composition of the regeneration medium (Gentile et al., 2002); or (3) 
52 inductive treatments prior to the regeneration phase (Antonelli and Druart, 1990). In a

53 set of experiments searching for a reliable regeneration method for adult material

54 (Pascual, 2003), we observed that an auxin pulse produced a clear effect improving

55 regeneration. In fact, auxin is clearly involved in morphogenesis since it regulates plant

56 cell division, elongation and differentiation (Chen, 2001). Here we test this in several

57 Prunus spp., and report the positive effect of a liquid 2,4-dichlorophenoxyacetic acid

58 (2,4-D) pulse on the adventitious regeneration of both, shoots and roots, as well as the

59 effect of a-naphthalene acetid acid (NAA) and 2,4-D in the regeneration medium. This

60 pulse can easily be adapted to other existing protocols, where different kinds of

61 treatments can be applied.

62

63 Materials and Methods

64 Plant material and in vitro culture

65 Shoot cultures of different Prunus rootstocks, established in vitro more than one-year

66 before from mature plants, were used. The rootstocks tested include the apricot A 843

67 (P. armeniaca L.), the almond x peach hybrid Adafuel (P. x amigdalo-persica (Weston)

68 Rheder), and the plum rootstocks Myrobalan 605 AD (P. cerasifera Ehrh.), Marianna

692624 (P. cerasifera Ehrh. x munsoniana Wight \& Hedr.), and Adesoto 101 (P. insititia

70 L.).

71

72 Effect of a liquid 2,4-D pulse

73 The effect of a liquid 2,4-D pulse on adventitious shoot or root regeneration was studied

74 using leaf explants from in vitro shoots of different rootstocks. They were subcultured

75 once a month into a modified DKW medium (Driver and Kuniyuki, 1984) with glycine

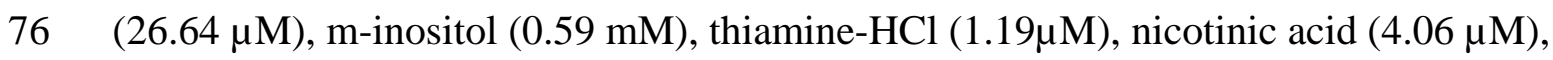


pyridoxine- $\mathrm{HCl}(2.43 \mu \mathrm{M})$, benzyl amino purine (BAP, $5 \mu \mathrm{M})$, indol 3- butyric acid (IBA, $0.5 \mu \mathrm{M}$ ), and sucrose $\left(30 \mathrm{~g} \cdot \mathrm{l}^{-1}\right)$. $\mathrm{pH}$ was adjusted to 5.5 before adding agar (DifcoBacto) at $7 \mathrm{~g} \cdot \mathrm{l}^{-1}$. Basal, medium and tip leaf explants were obtained by making two transverse cuts perpendicular to the midrib. Leaves were excised under the dissecting microscope to avoid taking stem tissues surrounding the petiole. Leaf explants were placed in Petri dishes (adaxial side up) on regeneration medium immediately (control), or after a short induction treatment (90 min) on liquid MS medium (Murashige and Skoog, 1962) supplemented with 2,4-D (1.7 $\mu \mathrm{M})$. The regeneration medium consisted on a modified Quoirin \& Lepoivre (1977) medium (QL), with half strength macro salts, thiamine-HCl $(3 \mu \mathrm{M})$, NAA $(2.6 \mu \mathrm{M})$, BAP $(3.5 \mu \mathrm{M})$ and sucrose $\left(20 \mathrm{~g} \cdot \mathrm{l}^{-1}\right)$. PPM $^{\circledR}$ ('Plant Preservative Mixture'; Plant Cell Technology, Washington, DC, USA) was added at $0.5 \mathrm{ml} \cdot \mathrm{l}^{-1}$. The $\mathrm{pH}$ was adjusted at 5.8, and the medium was gellified with Phytagel $\left(2.8 \mathrm{~g} \cdot \mathrm{l}^{-1}\right)$. All leaves from one in vitro cultured shoot were used per treatment and two replicates were made, thus, a variable number of leaf explants were used: A 843, 12 and 12 leaves (control) and 12 and 14 leaves (2,4-D pulse); Marianna 2624, 20 and 15 leaves (control) and 16 and 14 leaves (2,4-D pulse); Myrobalan 605 AD, 14 and 14 leaves (control) and 12 and 16 leaves (2,4-D pulse); Adafuel, 25 and 30 leaves (control) and 20 and 21 leaves (2,4-D pulse); and Adesoto 101, 14 and 14 leaves (control) and 21 and 20 (2,4-D pulse). Regenerated organs were scored after a 90 days culture period.

\section{Effect of the auxins NAA and 2,4-D in the regeneration medium after the pulse}

The regeneration medium tested in the previous experiment was compared with a similar one but containing 2,4-D instead of NAA at the same concentration (2.6 $\mu \mathrm{M})$. Leaves from different rootstocks grown on MS proliferation medium were used: 
102 Adafuel, Adesoto 101, Marianna 2624, and Myrobalan 605 AD. Forty basal, medium

103 and tip leaf explants, as well as 30 whole leaves per treatment were placed in Petri

104 dishes (adaxial side up) after a short induction treatment (90 min) on liquid MS medium

105 supplemented with 2,4-D $(1.7 \mu \mathrm{M})$ as in the previous experiment. The explants were

106 subcultured to the same fresh media at 30 days intervals and regeneration was scored

107 after 90 days. The experiment was repeated three times.

108

109

110 Data analysis

111 Adventitious regeneration was scored as the percentage of explants with shoot or root

112 formation. A completely randomized design was applied and an ANOVA of the

113 transformed data (arcsine transformation) was performed to study the treatment effects

114 on regeneration. Treatment means were compared when appropriated with Duncan’s

115 Multiple Range test. SPSS statistical software (SPSS Inc., Chicago, USA) was used.

117 Results

118 Effect of a liquid 2,4-D pulse

119 A liquid 2,4-D pulse (90 min) of leaf explants placed in a liquid MS medium with 2,4-D

$120(1.7 \mu \mathrm{M})$ greatly increased adventitious shoot and root regeneration from leaf explants

121 of different Prunus rootstocks, but regeneration was genotype dependent. Furthermore,

122 while the same tissue -leaf explants- were used in all genotypes, a differentiated

123 response was obtained. Whereas shoots were formed on callus tissues that grew on leaf

124 explants of Marianna 2624 (Figure 1, A) and Myrobalan 605 AD, roots were formed in

125 Adafuel (Figure 1, B), and in a less extent in Adesoto 101 explants. In contrast, in spite

126 of the callus tissues formed, the apricot A 843 did not differentiate any shoot or root. 

regeneration. The effect of the induction treatment, increasing shoot regeneration, was significant $(\mathrm{P}<0.01)$ (Table 1, Figure 2 top). An average of $42.9 \%$ of basal explants exhibited shoot regeneration after the application of the auxin pulse, 2.8-fold that of control explants, and almost twice that of treated medium or tip leaf explants. The pulse treatment in Myrobalan 605 AD basal leaf explants showed a similar positive effect on shoot regeneration that reached a $12.5 \%$, more than 3 -fold that of control explants. However, this effect was not found in medium- or tip-leaf explants (Figure 2, middle), and these differences were not statistically significant (Table 1). Adafuel regenerated more roots after the induction treatment, being in basal explants more than 3-fold that of the control, in a similar way as the previous rootstocks, and this effect was statistically significant $(\mathrm{P}<0.05)$ (Figure 2 bottom, Table 1). Treated basal leaf explants regenerated more roots than medium or tip leaf explants, but these differences were not statistically significant. However, shoot regeneration was not obtained, in contrast to Marianna 2624 and Myrobalan 605 AD. Adesoto 101

142 showed, as Adafuel, only root regeneration, but in a small rate (1 basal and 2 medium

143 regenerated leaf explants when the pulse was applied, and only 1 basal leaf explant in 144 the control). Regeneration was not affected by the leaf age, since no differences between the leaves taken from a shoot were noticed in both, shoot or root regeneration. Most of the

147 differentiated adventitious buds developed into normal shoots that were excised and

148 successfully micropropagated in a MS multiplication medium, and then acclimatized 149 and transplanted to soil, where regenerated plants were indistinguishable from mother plants (Figure 1, C-F). 
Effect of the auxins NAA and 2,4-D in the regeneration medium after the pulse The hormonal composition of the regeneration medium greatly influenced regeneration after the pulse treatment. Marianna 2624 yielded the highest regeneration rate (58.9\%) when whole leaves were placed on regeneration medium with NAA and BAP (Figure 3, top). Both, the hormonal composition of the regeneration medium and the type of leaf explant had a significant effect on shoot regeneration for this rootstock (Table 2). The NAA + BAP medium was more effective than the 2,4-D + BAP medium, giving higher percentages of regeneration in all leaf explants, and these differences were statistically significant $(\mathrm{P}<0.001)$. In addition, whole leaves and basal explants significantly regenerated more shoots than medium and tip leaf segments $(\mathrm{P}<0.001)$. Myrobalan 605AD leaf explants regenerated shoots from whole, and basal-leaf explants, in both regeneration media, and from medium-leaf explants in 2,4-D + BAP medium. However no shoot regeneration was obtained from tip-leaf explants (Figure 3, bottom).

Adesoto 101 formed few shoots in all explants but in the tip of the leaves in the NAA + 2,4-D regeneration medium: 3 shoots in both whole and basal explants, and only one in medium explants. However, only one shoot was formed in a whole leaf when the regeneration medium included 2,4-D.

Adafuel leaf explants failed to form adventitious shoots in any regeneration medium, and only few roots were obtained on the 2,4-D + BAP medium: 2 roots in whole leaves and 1 root in basal explants. 


\section{Discussion}

176 Data presented here show a striking improvement of adventitious organ regeneration

177 (shoots and roots) from leaf explants of different clonal fruit-tree rootstocks cultured in

178 vitro after an auxin pulse treatment. A high percentage of explants (up to 58.9\%)

179 showing shoot regeneration was obtained from whole and basal leaf explants of

180 Marianna 2624, a widely used rootstock, which would facilitate the application of

181 biotechnology to fruit trees. The method is based on an auxin pulse of the explants

182 applied before being placed on a regeneration medium under standard culture

183 conditions. Previous reports with woody fruit trees have described laborious

184 regeneration procedures suggesting that regeneration seems to be affected by several

185 factors that interact between them, as in P. canescens (Antonelli and Druart, 1990), apricot and plum (Escalettes and Dosba, 1993), or peach (Gentile et al., 2002). Here, we describe a simple protocol that diminish explant manipulation. The use of liquid induction treatments were reported previously but under different experimental conditions. Thus, a two-days 2,4-D induction treatment was effective in $P$. canescens

190 shoot regeneration (Antonelli and Druart, 1990). On the other hand, the use of liquid

191 pulses (two hours) was reported earlier in gymnosperms utilizing high concentrations of cytokinins (BA or TDZ) to stimulate epidermal cell division and bud formation in Picea abies embryos (Arnold et al., 1988) and Douglas fir cotyledons (Goldfarb et al., 1991).

194 The positive effect of a brief passage of the explants in liquid medium has to be studied

195 in depth, since several significant changes in either cytoplasm density, complexity of

196 vacuoles, and porosity of cell membranes of mesophyl cells, have been described in 197 apple and related to an improvement of shoot regeneration and plant transformation 198 (Sriskandarajah and Goodwin, 1998). 
In this work we have shown that whole leaves have performed better than leaf segments in Marianna 2624, and no previous reports on that statement have been found.

201 The type of leaf explant used affected regeneration rate when a pulse was used, being

202 the basal part, including the petiole, the most reactive leaf part for both shoot and root

203 regeneration. Whole leaves and basal leaf explants showed a significantly better

204 regeneration than medium or tip leaf explants. In addition, basal treated explants

205 regenerated more shoots than medium or tip leaf explants in Marianna 2624 and Myrobalan $605 \mathrm{AD}$, as well as roots in Adafuel, but these differences faded when comparing control explants, suggesting that basal tissues in the petiole area were stimulated by the auxin pulse more than other leaf tissues. Care has been taken to avoid the inclusion of meristematic cells, from developing axillary buds next to the petiole,

210 when the leaf explants were obtained, therefore, regeneration took place exclusively

211 from leaf tissues. However, no statistically significant differences between leaf

212 segments were found in the first experiment, indicating that more experimental work

213 would be needed to clarify this effect. Other reports have described higher regeneration

214 from basal explants, being the proximity of the petiole or the petiole itself the most

215 morphogenic part (Antonelli and Druart, 1990; Druart, 1990a; Escalettes and Dosba, 216 1993; Yepes and Aldwinckle, 1994). In contrast, Sarwar and Skirvin (1997) described

217 in apple that mid leaf segments regenerated better than basal explants, showing tip 218 explants the lowest regeneration rate, and they suggested that it could be related to the 219 presence of two cut surfaces in mid segments that could increase the absorption of 220 media components. However, this effect was not found in our conditions, where shoots arose from callus tissues that were in contact with the culture medium. A gradient on shoot regeneration capacity was described in apple by Welander (1988) who found the

223 lowest regeneration in the tip, increasing towards the base. In our work, a gradient on 
the regeneration competence cannot be concluded, since no significant differences in the regeneration rate were found between the treated explants. The second experiment of this work, which confirms the positive effect of the auxin pulse, showed that whole leaves and basal leaf explants of Marianna 2624 regenerated significantly more shoots than medium or tip leaf segments. But whole leaves have performed better than basal leaf explants, suggesting a possible detrimental effect of wounding or a beneficial effect of the presence of a higher amount of leaf tissues. Both, whole and basal leaf explants exhibited high variability (Figure 3, top) that impeded to find a significant difference between their transformed mean values with Duncan’s Multiple Range test. The election of whole leaves as explants simplify the protocol minimizing the manipulations of plant material.

Previous reports found a detrimental effect of leaf age on regeneration. Thus, it is a common practice to use only the youngest leaves: as in almond (Miguel et al., 1996), apricot (Druart, 1990a; Escalettes and Dosba, 1993), cherry (Druart, 1990b; Hammatt, 1993), peach (Gentile et al., 2002; Declerck and Korban, 1996), and in plum (Bassi and Cossio, 1991; Escalettes and Dosba, 1993). However, in the first experiment of this work all leaves from each donor shoot were used and no effect of leaf age on regeneration were noticed, which suggests that the competent plant material is not restricted to the youngest leaves when the 2,4-D pulse is applied, increasing the explant availability.

The role of auxin in regeneration has been stressed here, both in the pulse treatment and in the regeneration medium, NAA being an effective auxin when combined with BAP after the 2,4-D pulse. However, the presence of 2,4-D in the regeneration medium decreased the regeneration rates obtained, suggesting that 2,4-D is effective only as a pulse treatment to stimulate the start of the morphogenetic response. 
250 the experimental conditions tested here, shoots were obtained in the plum rootstocks

251 Marianna 2624 and Myrobalan 605 AD, whereas the almond x peach hybrid Adafuel

252 formed only roots. The plum rootstock Adesoto 101 regenerated shoots or roots

253 depending on the experiment, but only in very few explants. No clear explanation is

254 available to account for this fact since the same plant material and the same protocol

255 was applied to these genotypes.

256 We have found here that the growth regulators combination in the regeneration

257 medium, combined to the auxin pulse, was competent for Marianna 2624 shoot

258 regeneration, with regeneration rates that suggests the possible use of this protocol for

259 biotechnological applications. Nevertheless, in spite of the positive effect of the auxin

260 pulse on regeneration, the protocol is not applicable yet to other rootstocks to get

261 satisfactory regeneration rates, so more work is necessary in these rootstocks to fit their

262 requirements. The auxin pulse can easily be adapted to other existing protocols to study

263 its possible beneficial effect to expand the use of biotechnology to adult stone-fruit trees

264 in a similar way as it was done with juvenile tissues, where the expression of genes for

265 agricultural traits has been performed (Scorza et al., 1995b).

266

\section{Acknowledgements}

268

269 This research was made possible by financial support of Spain’s CICYT grants no.

270 AGF98-0277-C04-01, AGL2001-2414-C04-01 and AGL2002-03231. One of us, LP,

271 held a fellowship from the Gobierno de Navarra (Spain).

272

273 


\section{References}

275 Ainsley P.J., Collins G.G., Sedgley M., 2000. Adventitious shoot regeneration from leaf 276 explants of almond (Prunus dulcis Mill.). In Vitro Cell. Dev. Biol.-Plant 36, 470$277 \quad 474$.

278 Antonelli M., Druart Ph., 1990. The use of a brief 24-D treatment to induce leaf 279 regeneration on Prunus canescens Bois. Acta Hortic. 280, 45-50.

280 Arnold S. von, Alsterborg E., Walles B., 1988. Micromorphological studies of 281 adventitious bud formation on Picea abies embryos treated with cytokinin. Physiol. $282 \quad$ Plant. 72, 248-256.

283 Bassi G., Cossio F., 1991. In vitro shoot regeneration of "Bluefre" and "Susina di Dro" 284 prune cultivars (Prunus domestica L.). Acta Hort. 289, 81-84.

285 Chen J.G., 2001. Dual auxin signaling pathways control cell elongation and division. J. 286 Plant Growth Reg. 20, 255-264.

287 Declerck V., Korban S.S., 1996. Influence of growth regulators and carbon sources on 288 callus induction, growth and morphogenesis from leaf tissues of peach (Prunus 289 persica L Batsch). J. Hort. Sci. 71, 49-55.

290 Driver J.A., Kuniyuki A.H., 1984. In vitro propagation of Paradox walnut rootstock. 291 Plant Cell Tiss. Organ Cult. 30, 135-140.

Druart Ph., 1990a. Effect of culture conditions and leaf selection on organogenesis of Malus domestica cv. McIntosh "Wijcik" and Prunus canescens Bois GM79. Acta Hort. 280, 117-124.

295 Druart Ph., 1990b. Improvement of somatic embryogenesis of the cherry dwarf 296 rootstock Inmil/GM9 by the use of different carbon sources. Acta Hort. 280, 125297 129.

298 Escalettes V., Dosba F., 1993. In vitro adventitious shoot regeneration from leaves of 
Prunus_spp. Plant Sci. 90, 201-209.

300 Grant N.J., Hammat N., 2000. Adventitious shoot development from wild cherry

301 (Prunus avium L.) leaves. New Forest 20, 287-295.

302 Gentile A., Monticelli S., Damiano C., 2002. Adventitious shoot regeneration in peach 303 [Prunus persica (L.) Batsch]. Plant Cell Rep. 20, 1011-1016.

304 Goldfarb B., Howe G.T., Bailey L.M., Strauss, S.H., Zaerr J.B., 1991. A liquid 305 cytokinin pulse induces adventitious shoot formation from Douglas-fir cotyledons. $306 \quad$ Plant Cell Rep. 10, 156-160.

307 Gutierrez-Pesce P., Taylor K., Muleo R., Rugini E., 1998. Somatic embryogenesis and 308 shoot regeneration from transgenic roots of the cherry rootstock Colt (Prunus avium $309 \quad x$ P. pseudocerasus) mediated by pRi 1855 T-DNA of Agrobacterium rhizogenes. $310 \quad$ Plant Cell Rep. 17, 574-580.

311 Hammatt N., 1993. Micropropagation of fastigiate bird cherry (Prunus padus L) and 312 adventitious shoot formation from leaves. J. Hort. Sci. 68, 975-981.

313 Hammatt N., Grant N.J., 1998. Shoot regeneration from leaves of Prunus serotina Ehrh. 314 (black cherry) and P. avium L. (wild cherry). Plant Cell Rep. 17, 526-530.

315 Miguel C.M., Druart Ph., Oliveira M.M., 1996. Shoot regeneration from adventitious 316 buds induced on juvenile and adult almond (Prunus dulcis Mill.) explants. In Vitro 317 Cell. Dev. Biol.-Plant 32, 148-153.

318 Murashige T., Skoog F., 1962. A revised medium for rapid growth and bioassays with 319 tobacco tissue cultures. Physiol. Plant. 15, 473-497.

320 Pascual L., 2003. Regeneración adventicia de especies frutales del género Prunus para 321 la aplicación de métodos biotecnológicos. PhD Thesis. Pamplona, Spain: Navarra $322 \quad$ University. 
Perez S., Moore J.N., 1985. Prezygotic endogenous barriers to interspecific hybridization in Prunus. J. Amer. Soc. Hort. Sci. 110, 267-273.

Perez-Tornero O., Egea J., Vanoostende A., Burgos L., 2000. Assessment of factors affecting adventitious shoot regeneration from in vitro cultured leaves of apricot. Plant Sci. 158, 61-70.

Quoirin M., Lepoivre P., 1977. Etudes de milieux adaptés aux cultures in vitro de Prunus. Acta Hort. 78, 437-442.

Rajasekaran K., Mullins M.G., 1982. Regeneration of grapevines by aseptic methods. Comb. Proc. Int. Plant Prop. Soc. 31, 213-218.

Sarwar M. and Skirvin R.M., 1997. Effect of thidiazuron and 6-benzylaminopurine on adventitious shoot regeneration from leaves of three strains of `McIntosh' apple

Scorza R., Hammerschlag F.A., Zimmerman T.W., 1995a. Genetic transformation in

Scorza R., Levy L., Damsteegt V., Yepes L.M., Cordts J., Hadidi A., Slightom J., Gonsalves D., 1995b. Transformation of plum with the papaya ringspot virus coat protein gene and reaction of transgenic plants to plum pox virus. J. Amer. Soc. Hort. Sci. 120, 943-952.

Sriskandarajah S., Goodwin P., 1998. Conditioning promotes regeneration and transformation in apple leaf explants. Plant Cell Tiss. Organ Cult. 53, 1-11.

Tang H.R., Ren Z.L., Renstle G., Krczal G., 2002. Plant regeneration from leaves of sweet and sour cherry cultivars. Sci. Hort. 93, 235-244. 
Welander M., 1988. Plant regeneration from leaf and stem segments of shoots raised in

348 vitro from mature apple trees. J. Plant Physiol. 132, 737-744.

349 Yepes L.M., Aldwinckle H.S., 1994. Factors that affect leaf regeneration efficieny in 350 apple, and effect of antibiotics in morphogenesis. Plant Cell Tiss. Organ Cult. 37, $351 \quad 257-269$

352

353

354 Table 1. ANOVA table of the effects of leaf explant type and a 2,4-D pulse treatment 355 on Marianna 2624 and Myrobalan 605 AD shoot regeneration, as well as in Adafuel

356 root regeneration, with F-values and significance

357

\begin{tabular}{lrrrr} 
Source & d.f. & \multicolumn{1}{c}{ S.S. } & \multicolumn{1}{c}{$F$} & \multicolumn{1}{c}{$P$} \\
\hline Marianna 2624 & & & & \\
\hline Explant type & 2 & 173.34 & 3.89 & 0.083 \\
Pulse treatment & 1 & 437.53 & 19.63 & 0.004 \\
Interaction & 2 & 66.62 & 1.49 & 0.30 \\
Error & 6 & 133.76 & & \\
\hline Myrobalan 605 AD & & & & \\
\hline Explant type & 2 & 52.81 & 0.36 & 0.71 \\
Pulse treatment & 1 & 27.47 & 0.37 & 0.56 \\
Interaction & 2 & 52.81 & 0.36 & 0.71 \\
Error & 6 & 443.28 & & \\
\hline Adafuel & & & & \\
\hline Explant type & 2 & 140.76 & 0.78 & 0.50 \\
Pulse treatment & 1 & 978.08 & 10.82 & 0.017 \\
Interaction & 2 & 2.81 & 0.02 & 0.99 \\
Error & 6 & 542.92 & & \\
\hline
\end{tabular}

358

359 
361 Table 2. ANOVA table of the effects of leaf explant type and the growth regulatros

362 combiantion in the regeneration medium on Marianna 2624 and Myrobalan 605 AD

363 shoot regeneration, with F-values and significance.

364

\begin{tabular}{lcrrr} 
Source & d.f. & \multicolumn{1}{c}{ S.S. } & \multicolumn{1}{c}{$F$} & $P$ \\
\hline Marianna 2624 & & & & \\
\hline Explant type & 3 & 1293.20 & 9.39 & 0.001 \\
Regeneration medium & 1 & 5554.67 & 120.93 & 0.000 \\
Interaction & 3 & 143.91 & 1.04 & 0.400 \\
Error & 16 & 734.92 & & \\
\hline Myrobalan 605 AD & & & & \\
\hline Explant type & 3 & 304.03 & 2.090 & 0.14 \\
Regeneration medium & 1 & 0.70 & 0.014 & 0.91 \\
Interaction & 3 & 54.45 & 0.374 & 0.78 \\
Error & 16 & 775.67 & & \\
\hline
\end{tabular}

365

366

367 
Figure captions

369

370 Figure 1. A) Adventitious shoot regeneration from a Marianna 2624 medium leaf

371 explant after a 2,4-D pulse (1.7 $\mu M$, $90 \mathrm{~min})$. B) Adventitious root regeneration from

372 Adafuel tip leaf explants after the 2,4-D pulse. C) Adventitious shoot regeneration from

373 a Marianna 2624 basal leaf explant. D) Marianna 2624 shoots developed from

374 adventitious buds and ready for micropropagation. E) Multiplication phase of

375 Marianna 2624 regenerated shoots in vitro. F) Potted in vitro regenerated Marianna

3762624 plants after the acclimatization in the greenhouse.

377

378 Figure 2. Shoot regeneration percentages from leaf explants of Marianna 2624 (top),

379 and Myrobalan $605 \mathrm{AD}$ (middle), and root regeneration percentages from Adafuel

380 (bottom), with or without a 2,4-D pulse treatment (bars: s.e.).

381

382 Figure 3. Shoot regeneration percentages from leaf explants of Marianna 2624 and 383 Myrobalan $605 \mathrm{AD}$ on regeneration media with a different auxin (NAA or 2,4-D) after a 384 2,4-D pulse treatment (bars: s.e.). Different letters showed significant differences 385 between leaf explant types after a Duncan's Multiple Range test $(P<0.05)$ of 386 transformed data. 
388

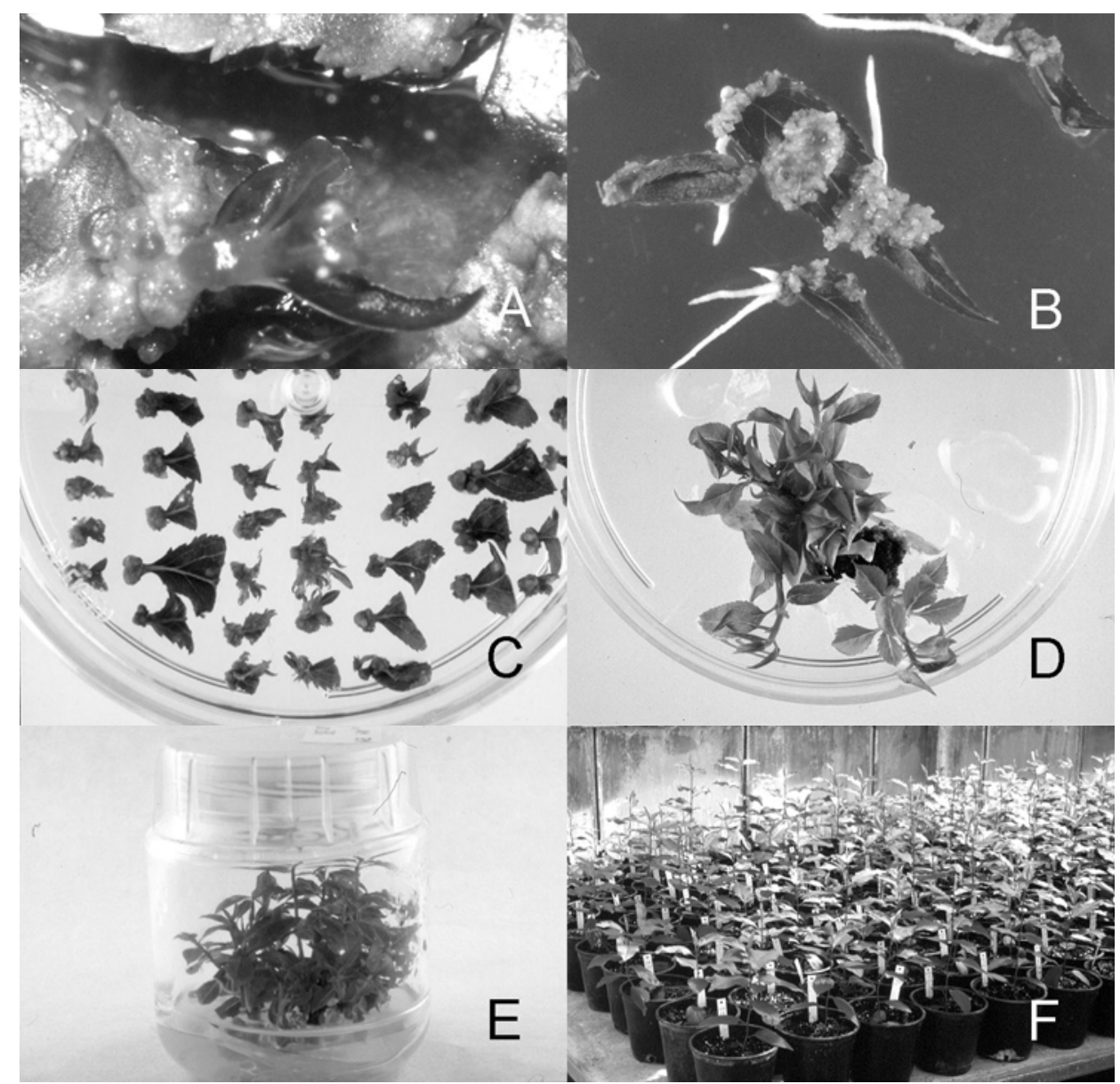

389

390

391

392

393

394

395

396 


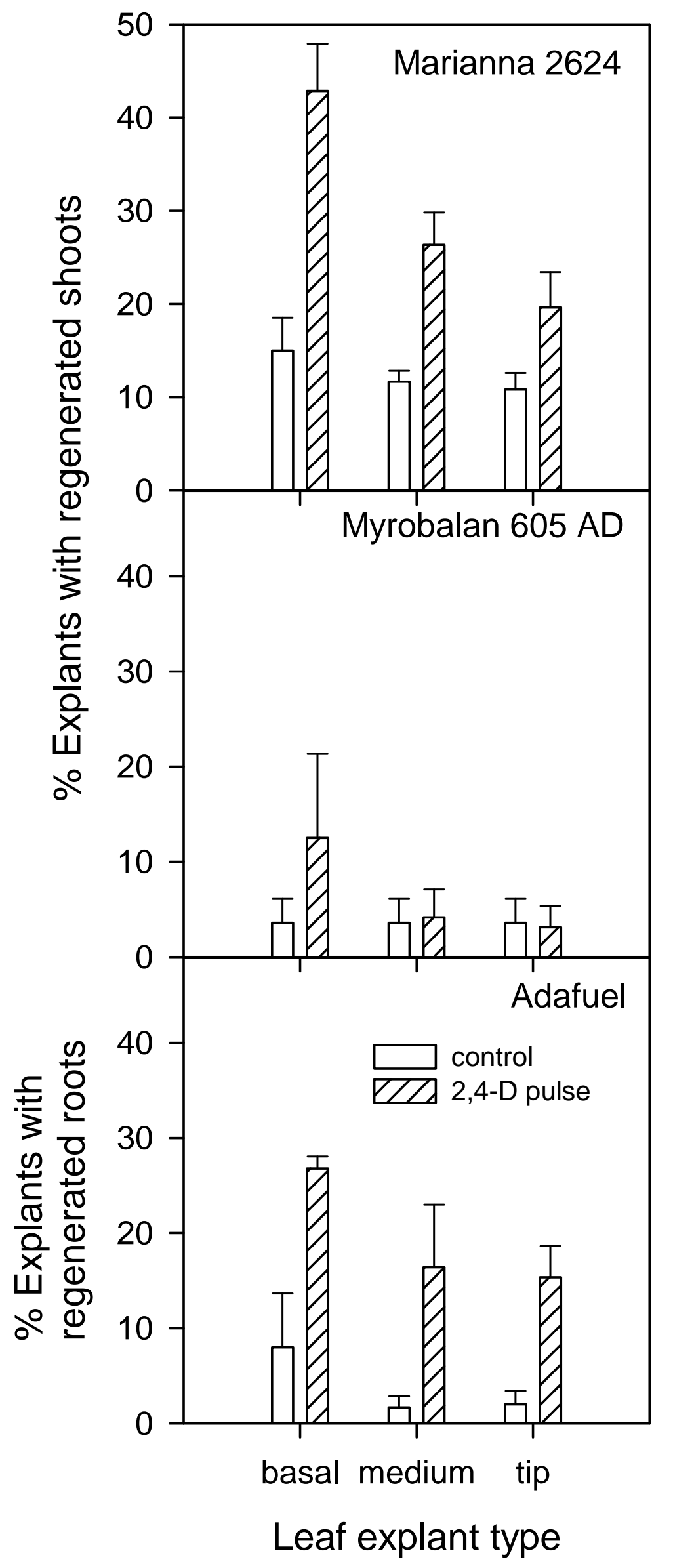




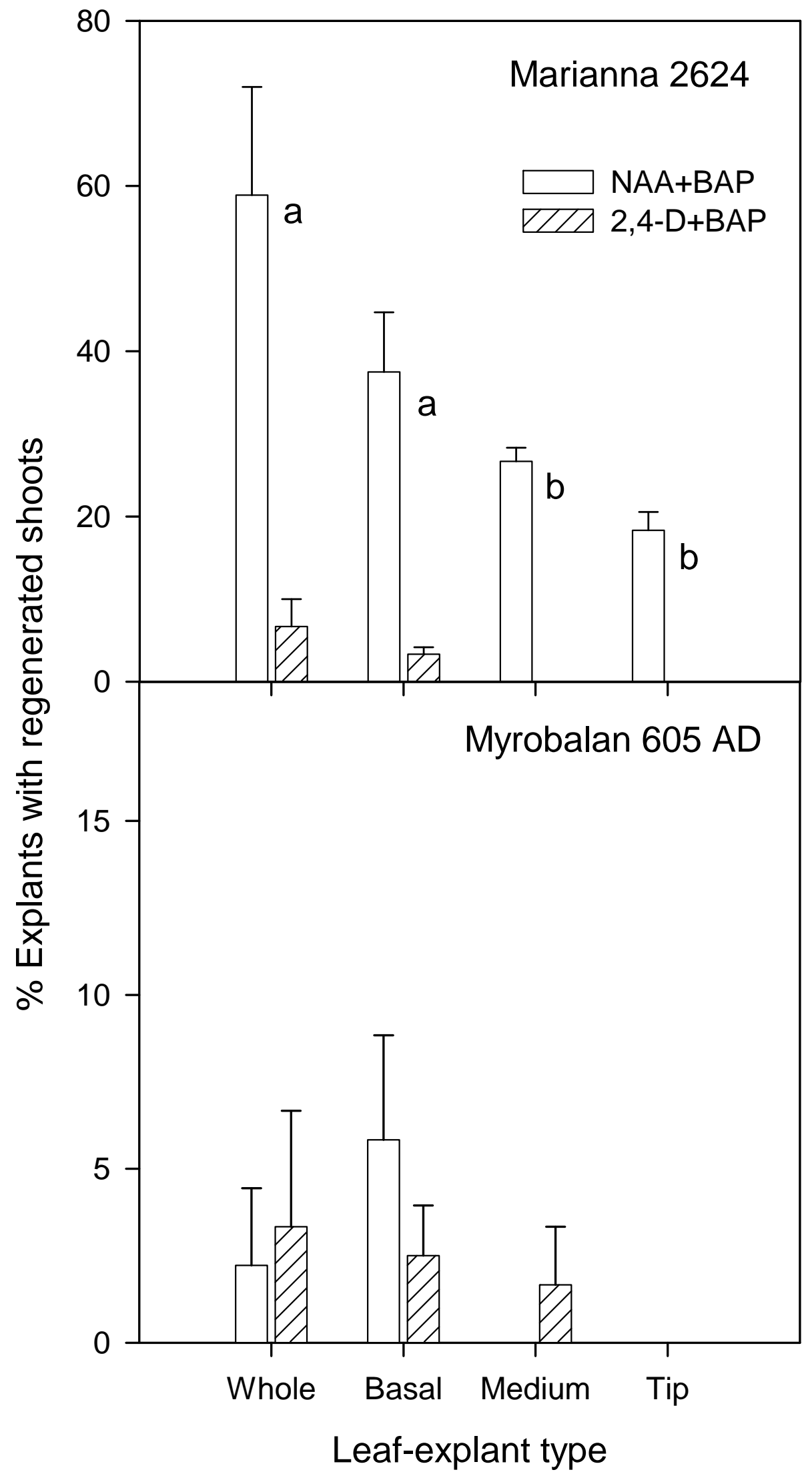

